\title{
Evaluation of Steric Effect of Hydroquinone, Tert-Butyl Hydroquinone and 2, 5-Ditert-Butyl Hydroquinone by using a Briggs-Rauscher Oscillator
}

\author{
Saif Ullah ${ }^{1}$, Waqar Uddin ${ }^{1}$, Gang Hu ${ }^{1, *}$, Muhammad Yasir Nawabi ${ }^{1}$, Rooh Ullah $^{2}$ \\ ${ }^{1}$ Department of Chemistry, Anhui University, Hefei, 230601, People's Republic of China \\ ${ }^{2}$ State Key Laboratory of Heavy Oil Processing, Petrochina Key Laboratory of Catalysis, China \\ University of Petroleum, Qingdao, 266555, China \\ *E-mail: hugang@ustc.edu
}

doi: $10.20964 / 2018.12 .78$

Received: 6 September 2018 / Accepted: 9 October 2018 / Published: 5 November 2018

\begin{abstract}
This article indicated a novel methodology of evaluation of steric effect of (hydroquinone (HQ), tertButyl hydroquinone (TBHQ) and 2, 5-ditert-butyl hydroquinone (DTBHQ)) by using a BriggsRauscher chemical oscillating system. The macro cyclic $[\mathrm{NiL}]\left(\mathrm{ClO}_{4}\right)_{2}$ complex catalyst with 5,7,7,12,14,14-hexamethyl-1,4,8,1,1-tetraazacyclotetradeca-4,1,1-diene as ligand is used. The calculated experimental data confirmed the diverse perturbation effects of all three additives towards the active Briggs-Rauscher oscillator in their concentration ranges from $5.0 \times 10^{-7} \mathrm{M}$ to $1.25 \times 10^{-5} \mathrm{M}$. Hydroquinone generate inhibition time $\left(\mathrm{t}_{\mathrm{in}}\right)$ higher than $\mathrm{t}-\mathrm{BHQ}$, whereas, no influence of 2,5-DBHQ were observed in Briggs-Rauscher system. Our claim for such differences in perturbation is due to the strong steric hindrance effect of these additives. The presence of bulky group (tertiary butyl) reduces the reactivity of the antioxidants by covering the active sides $\left(\mathrm{OH}\right.$-group) from the attack of $\mathrm{HOO}^{\bullet}$ radical. Thus, Hydroquinone produced larger $t_{i n}$ because of absence of bulky group, the shorter $t_{\text {in }}$ of $t-$ BHQ due to the presence of one bulky group whereas, no $t_{\text {in }}$ of 2, 5-DBHQ because of two bulky groups attached. The perturbation reaction mechanism was discussed on the basis of FCA (FurrowCervellati-Amadori) model. The explanation mechanism is that both HQ and t-BHQ is oxidized by $\mathrm{HOO}^{\bullet}$ into their respective Quinone.
\end{abstract}

Keywords: Antioxidant; Briggs-Rauscher; Antioxidants; Inhibitory effect; Steric effect

\section{FULL TEXT}

(C) 2018 The Authors. Published by ESG (www.electrochemsci.org). This article is an open access article distributed under the terms and conditions of the Creative Commons Attribution license (http://creativecommons.org/licenses/by/4.0/). 